\title{
Desirability function based optimization of experimental data for air-water spray impingement cooling
}

\author{
Santosh Kumar Nayak a and Purna Chandra Mishra ${ }^{b^{*}}$
}

${ }^{a}$ School of Mechanical Engineering, KIIT University, Bhubaneswar- 751024, Odisha, India

${ }^{b}$ School of Mechanical Engineering, KIIT University, Bhubaneswar- 751024, Odisha, India

\section{H R O N I C L E}

Article history:

Received October 28, 2015

Received in revised format

November 28, 2015

Accepted January 17, 2016

Available online

January 20, 2016

Keywords:

Desirability function

Optimization

Spray

Impingement cooling

\section{A B S T R A C T}

The current research copes with the optimization of the surface heat transfer coefficients of a square mild steel test specimen by spray impingement cooling. A laboratory scale experimental setup was developed at School of Mechanical Engineering KIIT University, Odisha, India to investigate the role of various process parameters to enhance the heat transfer from the surface of the heated steal specimen. The mild steel plates of dimension $120 \mathrm{~mm} \times 120 \mathrm{~mm}$, and different thicknesses of $4 \mathrm{~mm}, 6 \mathrm{~mm}$ and $8 \mathrm{~mm}$ were used in the experiment. The effect of the process parameters such as thickness of the tested plate, nozzle to plate distance, air and water pressure upon the surface heat transfer coefficient (HTC) was optimized. The optimization of the controlling parameters was carried out by using the desirability functions. The Design Expert 8 software was used to analyze the experimental results. A new correlation was developed for optimization of the surface heat transfer coefficient.

\section{Introduction}

In present scenario, the modern constructions and fabrications required high strength and good workability steel. The most effective process upon which the mechanical properties of the steel depends is the Run out Table cooling. Generally, the multiphase microstructure of steels are controlled by very high cooling rates which is not possible with the conventional laminar jet cooling because of development of stable film boiling on the hot test surface which precludes the heat transfer. Several drawbacks of conventional laminar cooling lead to the development of Ultra-Fast cooling for removal of large heat flux from the hot surfaces. In air assisted spray impingement cooling technique, the compressed air is used to atomize the water particle into very tiny droplets and impinged on the hot surface to be cooled. Sprays make use of the momentum of liquid entering the spray nozzle to disintegrate into very high quality fragments, which strike separately upon the hot surface. The breakup of tiny droplets increases the surface area to volume ratio of the liquid and helps to produce a wellproportioned spatial distribution of heat removal both in the single-phase and nucleate boiling regimes.

* Corresponding author. Tel.: +91-674-6540805 (O)

E-mail address: pcmishrafme@kiit.ac.in (P.C. Mishra) 
Another main feature of spray impingement cooling is defermenting liquid separation from the surface during vigorous boiling. By bombarding the total surface with tiny droplets, the momentum of the individual droplet is more efficient at resisting the momentum of vapour perpendicular to the surface than a wall jet. Mudawar and Estes (1996) experimentally investigated the effect of nozzle height on critical heat flux for spray cooling of a heated square surface by full cone sprays of Fluorinert FC-72 and FC-87. The results revealed that the critical heat flux was peak for the spray strike area engraves the heated plane and the value is very small for small nozzle height. Díaz et al. (2013) carried out experiments on water droplet during a gas impact on a heated plane. Further they compared their experimental results with that of conjugate solution and volume of fluid (VOF) simulation results. They concluded that the temperature variation was diffusion dominated during the early stages because of the stagnant droplet impact velocity. Naz et al. (2013) had the objective of analysing the dynamics of water spray split, swirl formation, fragment size dispensation in situations where temperature and pressure vary continuously. They found that injection of thermal energy into the spray is the most important spray boundary condition. It strongly affects spray width, length, penetration and Weber Number. Seraj et al. (2013) had a study which reported an investigation on damped space arises because of the heat loss from aluminium surface under spray impingement at varied fluid flow rates, nozzle height. They have concluded that wetting did not start upon spray impingements and there was a delay in wetting initiation in spite of the instant wetting, observed in experiments with water circular jet. Galvan et al. (2013) investigated on the impact of the spray cone angle on heat transfer and film thickness. The conclusion that could be dragged out was that thermal performance decreases with increase in spray cone angle. Yu Hou et al. (2013) investigated on the phase transition spray heat transfer phenomena. They designed a R22 pressure spray cooling system for experimentation. They tested the cooling system at fixed spray pressure range between 0.6 MPa and 1.0MPa. The air atomized cooling provided a very high cooling rates and it could be applied to produce high strength steel run out table (ROT). Ravikumar et al. (2013) used different surfactant of various concentrations with water in spray cooling technique to embellish the cooling rate. The authors concluded from the results that both type and concentrations of surfactants have strong predominance on cooling rate and surfactant having less foam formability ability exile more heat from test heated surface. Lijun Houa et al. (2012) carried out investigation to check the heat transfer efficiency of water, nitrogen and quenching oil interms of temperature variance and cooling velocity. The result showed that the nitrogen-spray water had more cooling capacity compared to that of only water. Temperature variances between exteriorinterior surfaces in case of nitrogen water are less than water. They obtained a lesser thermal stress and thermal deformation of the object in case of nitrogen spray water quenching during testing at a fixed cooling velocity. Ebadian et al. (2011) investigated the removal techniques of high-heat-flux. Studies were done on micro channels, sprays, wettability effects, jet impingements. The experimentation has given the conclusion that High-Heat-flux can be removed by individual or hybrid methods using multiple cooling techniques. Wettability can increase heat transfer rate but that is affected by micro channels. Bahman et al. (2011) obtained heat transfer measurements on smooth flat surface with help of an array of micro heaters. The experiments were done for different nozzle to heater distance, operating pressure and different sub cooling levels. The conclusion clarifies that local impingement pressure plays a vital role in both single phase and multi-phase spray cooling. Wendelstorf et al. (2008) studied about the transfer of heat during the water spray cooling of clean surface using full cone nozzles $\left(V_{d}=14 \mathrm{~m} / \mathrm{s}, d_{d}=350 \mathrm{~lm}\right)$ within the parameter range of $V_{s}=3-30 \mathrm{Kg} /\left(\mathrm{m}^{2} . \mathrm{s}\right)$. The temperature was kept between $200-1100^{\circ} \mathrm{C}$. The stable film boiling regime depicts decreasing HTC with temperature difference. $11 \%$ better accuracy was achieved in the film boiling regime. The maximum heat flux was between $15.7 \mathrm{~kg} / \mathrm{m}^{2} \mathrm{~s}$ to $24.9 \mathrm{~kg} / \mathrm{m}^{2} \mathrm{~s}$. Pautsch and Shedd (2005) used different nozzle patters for parametric study of spray cooling method. They found that the configuration of bank of nozzles had no significant influence on the overall heat transfer capacity. Though the multi-jet arrays admitted for maximum heat fluxes, but did not utilized fluid more effectively because of interactions between neighbouring spray. Amir et al. (2014) used an analytical model for determination of critical droplet diameter in order to get an ultrafast cooling rate of $300{ }^{\circ} \mathrm{C}$. Fabbri and Dhir (2005) investigated the effect of micro jet arrays upon heat transfer by using water and FC40 as working fluid and obtained the 
maximum surface heat flux of $310 \mathrm{~W} / \mathrm{cm}^{2}$ with the help of $173.6 \mu \mathrm{m}$ diameter water jets with impinging velocity of $12.5 \mathrm{~m} / \mathrm{s}$ on a circular copper plate. Ravikumar et al. (2014) used aqueous polymer solution in spray cooling to enhance the surface heat flux as well as cooling rate and the optimum cooling rate found to be $253{ }^{0} \mathrm{C} / \mathrm{s}$ for an optimal polymer concentration. Though there are several process parameters that have influence on heat transfer, the current investigation is the optimization of the controlling parameters such as air-water pressure, nozzle tip to target spacing, and plate thickness on heat transfer efficiency of SIC.

\section{Experimental Methodology}

\subsection{Experimental setup}

The investigation was carried out with the help of a laboratory scale experimental setup developed at School of Mechanical Engineering KIIT University, Odisha, India as shown in Fig. 1 consists of several equipment, spray system, heating unit and a data acquisition system for temperature measurement. A reciprocating air compressor was used to supply compressed air to the spray setup for atomization of the water particle. The test specimens used in the investigations were of dimension $120 \mathrm{~mm}$ length and $120 \mathrm{~mm}$ width and of three different thickness such as $4 \mathrm{~mm}, 6 \mathrm{~mm}$ and $8 \mathrm{~mm}$ embedded with four Ktype thermocouples at various locations on the bottom surface of the specimen. The heating of the test plate was carried out with the help of an electric heater. The transient temperature data were recorded by the help of a CHINO data acquisition system and analysis of temperature data can be done through Zaila application software environment.

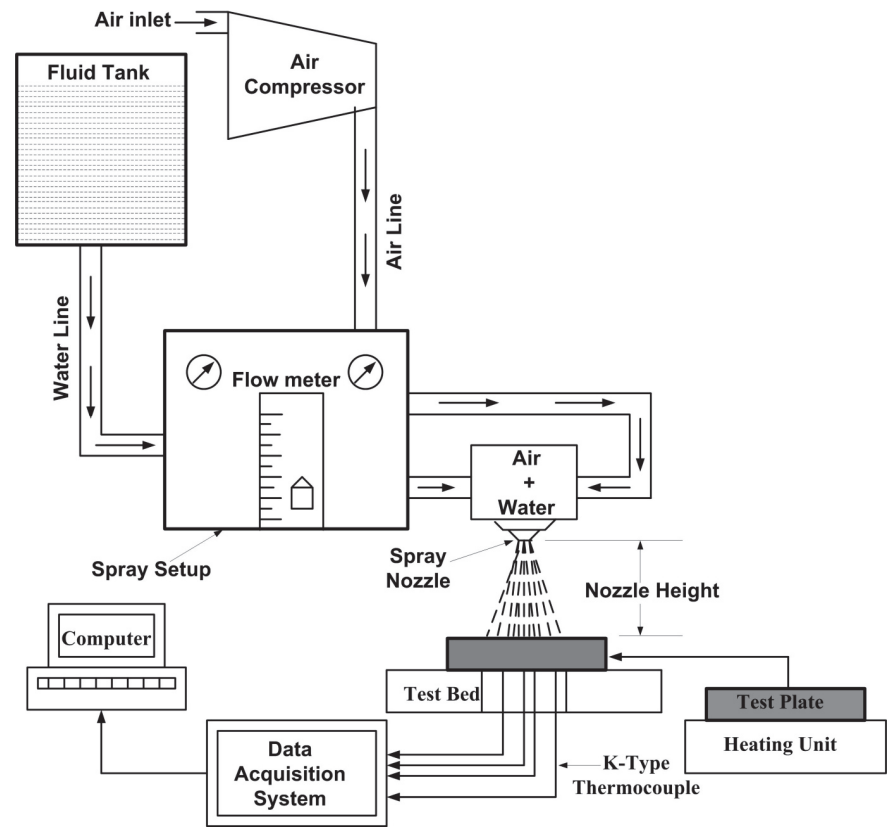

Fig. 1. Schematic of spray impingement cooling system

\subsection{Experimental Procedure}

Initially, the test plate was heated up to the desired temperature by the help of an electric heater. During the interval of heating process, all the requisite equipment and measurements were set to the required levels. When the plate reached the desired temperature i.e. $900{ }^{\circ} \mathrm{C}$, it was shifted to the test bed below the air-atomized spray nozzle. Then by switching on the spray apparatus, the heated plate was cooled because of impact of the air assisted tiny water droplets coming out of the spray nozzle. The cooling process was carried out at various sets of water and air pressures ranging from 0 bars to 4 bars with different nozzle heights of $120 \mathrm{~mm}, 180 \mathrm{~mm}$ and $240 \mathrm{~mm}$ respectively. Data acquisition system served 
as an effective tool for recording the transient temperature data. The Box-Behnken design of response surface methodology (RSM) is used, as it performs non-sequential experiments having fewer design points to get the experimental design matrix. Water pressure, air Pressure, plate thickness and nozzle height are the input parameters. Three levels of the input parameters are used i.e. Low (-1), Mid (0), High $(+1)$. Twenty seven experimental runs were obtained by the methodology to conduct the experiment. The Table 1 shows the input parameters with their levels and the coded design matrix. According to the experimental design matrix, 27 numbers of experiments were conducted at different process parameters. The outcomes of the investigations were computed systematically at various operating conditions with different process parameters. The Box Behnken RSM based Coded experimental design matrix is presented in Table 2.

Table 1

Input Parameters with their Coded value at different levels

\begin{tabular}{ccccc}
\hline Sl. NO & Input Parameter & $\begin{array}{c}\text { Low Level } \\
(-1)\end{array}$ & $\begin{array}{c}\text { Mid-Level } \\
(0)\end{array}$ & $\begin{array}{c}\text { High Level } \\
(+1)\end{array}$ \\
\hline 1 & & 2 & 3 & 4 \\
2 & Water Pressure & 2 & 3 & 4 \\
3 & Air Pressure & 4 & 6 & 8 \\
4 & Plate Thickness & 120 & 180 & 240 \\
\hline
\end{tabular}

Table 2

Box Behnken RSM based Coded Experimental Design Matrix

\begin{tabular}{|c|c|c|c|c|}
\hline Sl.No & A:Water Pressure $(\mathrm{Pw})$ & B:Air Pressure $(\mathrm{Pa})$ & C:Plate Thickness $(\mathrm{t})$ & D:Nozzle Height $(\mathrm{H})$ \\
\hline & bar & bar & $\mathrm{mm}$ & $\mathrm{mm}$ \\
\hline 1 & 1 & 0 & -1 & 0 \\
\hline 2 & 0 & 0 & -1 & 1 \\
\hline 3 & 1 & 0 & 0 & 1 \\
\hline 4 & 0 & -1 & 0 & -1 \\
\hline 5 & 0 & -1 & 1 & 0 \\
\hline 6 & -1 & -1 & 0 & 0 \\
\hline 7 & 0 & 0 & 1 & -1 \\
\hline 8 & -1 & 1 & 0 & 0 \\
\hline 9 & 0 & 0 & 0 & 0 \\
\hline 10 & 0 & -1 & 0 & 1 \\
\hline 11 & 0 & 1 & 0 & 1 \\
\hline 12 & -1 & 0 & -1 & 0 \\
\hline 13 & 0 & 1 & 0 & -1 \\
\hline 14 & 0 & 0 & 0 & 0 \\
\hline 15 & 0 & -1 & -1 & 0 \\
\hline 16 & 1 & 0 & 0 & -1 \\
\hline 17 & -1 & 0 & 0 & 1 \\
\hline 18 & 1 & -1 & 0 & 0 \\
\hline 19 & 0 & 0 & 0 & 0 \\
\hline 20 & 0 & 0 & 1 & 1 \\
\hline 21 & 0 & 0 & -1 & -1 \\
\hline 22 & 1 & 1 & 0 & 0 \\
\hline 23 & 0 & 1 & -1 & 0 \\
\hline 24 & 1 & 0 & 1 & 0 \\
\hline 25 & -1 & 0 & 0 & -1 \\
\hline 26 & 0 & 1 & 1 & 0 \\
\hline 27 & -1 & 0 & 1 & 0 \\
\hline
\end{tabular}

\subsection{Measurement of Response}

The convective heat transfer is the transfer of heat from one place to another by the bulk movement of fluids. Convection is usually the dominant form of heat transfer in liquids and gases. The convective heat transfer coefficient or film coefficient, in thermodynamics is the proportionality coefficient between the heat flux and the thermodynamic driving force for the flow of heat i.e. the temperature difference. It depends on conditions in the boundary layer which are influenced by surface geometry, the nature of the fluid motion, type of media, gas or liquid, the transport properties such as velocity, viscosity and other flow and temperature dependent properties. Cooling rate (CR) is one of the most important factors to determine the heat transfer characteristics during cooling of a heated steel plate by air assisted spray impingement cooling. 
From the computed transient temperature distribution curves for each thermocouple location, the corresponding optimum values of cooling rates were calculated by taking the peak values of temperature and time. The cooling rate can be determined by using Eq. (1). By putting the value of cooling rate in Eq. (2), the magnitude of HTC can be determined.

$$
C R=\frac{T_{1}-T_{2}}{t_{2}-t_{1}}{ }^{\circ} \mathrm{C} / \mathrm{Sec},
$$

where, $\mathrm{CR}$ is the maximum value of cooling rate in ${ }^{0} \mathrm{C} / \mathrm{Sec}$

$\mathrm{T}_{1}=$ Temperature at the beginning of the spray in ${ }^{0} \mathrm{C}$

$\mathrm{T}_{2}=$ Temperature at the end of the spray in ${ }^{0} \mathrm{C}$

$\mathrm{t}_{1}=$ Real spray time at the start of spray in Sec

$\mathrm{t}_{2}=$ Real spray time at the end of spray in Sec

Again,

$$
h_{c} \times A \times \Delta T=m \times C_{p} \times \frac{\partial T}{\partial t}
$$

where, $\Delta T=T_{s}-T_{c}, m=\rho \times V=\rho \times A \times \tau, \frac{\partial T}{\partial t}=$ Cooling Rate $=C R$ and $\tau=$ Thickness of the plate in meter.

Hence,

$$
h_{c}=\frac{\left(\rho \times C_{p} \times \tau \times C R\right)}{\left(T_{S}-T_{C}\right)}
$$

\subsection{Experimental Outcome}

In this study, the response is the surface heat transfer coefficient which can be computed by using the Eq. (2) at various operating conditions. The magnitude of the outcome at different set of process parameters were depicted in Table 3.

\begin{tabular}{|c|c|c|c|c|c|}
\hline S1. No. & $\begin{array}{c}\text { Factor } 1 \\
\text { A:Water } \\
\text { Pressure }(\mathrm{Pw})\end{array}$ & $\begin{array}{c}\text { Factor } 2 \\
\text { B:Air } \\
\text { Pressure }(\mathrm{Pa})\end{array}$ & $\begin{array}{c}\text { Factor } 3 \\
\text { C:Plate } \\
\text { Thickness(t) }\end{array}$ & $\begin{array}{c}\text { Factor } 4 \\
\text { D:Nozzle } \\
\text { Height(H) }\end{array}$ & $\begin{array}{c}\text { Response } 1 \\
\text { Heat Transfer } \\
\text { Coefficient(HTC) }\end{array}$ \\
\hline & bar & bar & $\mathrm{mm}$ & $\mathrm{mm}$ & watt $/ \mathrm{m}^{2} . \mathrm{C}$ \\
\hline 1 & 4.00 & 3.00 & 4.00 & 180.00 & 1882.99 \\
\hline 2 & 3.00 & 3.00 & 4.00 & 240.00 & 4944.64 \\
\hline 3 & 4.00 & 3.00 & 6.00 & 240.00 & 3197.98 \\
\hline 4 & 3.00 & 2.00 & 6.00 & 120.00 & 2354.48 \\
\hline 5 & 3.00 & 2.00 & 8.00 & 180.00 & 2333.06 \\
\hline 6 & 2.00 & 2.00 & 6.00 & 180.00 & 1083.79 \\
\hline 7 & 3.00 & 3.00 & 8.00 & 120.00 & 2333.06 \\
\hline 8 & 2.00 & 4.00 & 6.00 & 180.00 & 1121.93 \\
\hline 9 & 3.00 & 3.00 & 6.00 & 180.00 & 1423.25 \\
\hline 10 & 3.00 & 2.00 & 6.00 & 240.00 & 1788.81 \\
\hline 11 & 3.00 & 4.00 & 6.00 & 240.00 & 1466.96 \\
\hline 12 & 2.00 & 3.00 & 4.00 & 180.00 & 3900.97 \\
\hline 13 & 3.00 & 4.00 & 6.00 & 120.00 & 2167.29 \\
\hline 14 & 3.00 & 3.00 & 6.00 & 180.00 & 2028.81 \\
\hline 15 & 3.00 & 2.00 & 4.00 & 180.00 & 5778.86 \\
\hline 16 & 4.00 & 3.00 & 6.00 & 120.00 & 2414.03 \\
\hline 17 & 2.00 & 3.00 & 6.00 & 240.00 & 1765.93 \\
\hline 18 & 4.00 & 2.00 & 6.00 & 180.00 & 1851.6 \\
\hline 19 & 3.00 & 3.00 & 6.00 & 180.00 & 2191.94 \\
\hline 20 & 3.00 & 3.00 & 8.00 & 240.00 & 1997.03 \\
\hline 21 & 3.00 & 3.00 & 4.00 & 120.00 & 3415.09 \\
\hline 22 & 4.00 & 4.00 & 6.00 & 180.00 & 1907.05 \\
\hline 23 & 3.00 & 4.00 & 4.00 & 180.00 & 3290.1 \\
\hline 24 & 4.00 & 3.00 & 8.00 & 180.00 & 2676.52 \\
\hline 25 & 2.00 & 3.00 & 6.00 & 120.00 & 1135.72 \\
\hline 26 & 3.00 & 4.00 & 8.00 & 180.00 & 2290.81 \\
\hline 27 & 2.00 & 3.00 & 8.00 & 180.00 & 1842.9 \\
\hline
\end{tabular}

\section{Table 3}

Magnitude of the outcomes 


\section{Results and Discussion}

\subsection{Empirical Model Development}

Regression analysis is done and the below given quadratic model was obtained from the experimental data obtained:

$$
\begin{aligned}
& \mathrm{HTC}=22095-217 \mathrm{Pw}-2189 \mathrm{~Pa}-5261 \mathrm{t}+2.3 \mathrm{H}-299 \mathrm{Pw} \times \mathrm{Pw}+33 \mathrm{~Pa} \times \mathrm{Pa}+297.3 \mathrm{t} \times \mathrm{t} \\
& \quad+0.0628 \mathrm{H} \times \mathrm{H}+4 \mathrm{Pw} \times \mathrm{Pa}+356 \mathrm{Pw} \times \mathrm{t}+0.64 \mathrm{Pw} \times \mathrm{H}+306 \mathrm{~Pa} \times \mathrm{t}-0.56 \mathrm{~Pa} \times \mathrm{H}-3.89 \mathrm{t} \times \mathrm{H} \\
& \text { where } \mathrm{Pw}=\text { Water Pressure; } \mathrm{Pa}=\text { Air Pressure; } \mathrm{t}=\text { Plate Thickness; } \mathrm{H}=\text { Nozzle Height. }
\end{aligned}
$$

\subsection{Response Surface Analysis}

The statistical analysis of the experimental results was done by Design Expert 8 software. Fig. 2 shows the variation of HTC with respect to air pressure and water pressure. It is evident that the variation of HTC with variation of air pressure is less significant than water pressure. Highest value of HTC in this condition is achieved at low level of air pressure and high level of water pressure and vice-versa. This is because of when the air pressure is more; there is more effective atomization of the water particle and maximum blown up of the water vapour which reduces the heat transfer from the plate surface. Fig. 3 shows the variation of HTC with respect to water pressure and plate thickness. It is evident that the variation of HTC with variation of water pressure and air pressure is significant but inverse in nature i.e. with increase in plate thickness HTC decreases and with increase in water pressure HTC increases. Fig. 4 shows the variation of HTC with respect to water pressure and nozzle height. It is evident that the variation of HTC with variation of nozzle height is less significant than water pressure. The maximum value of HTC is achieved at high levels of both the inputs.

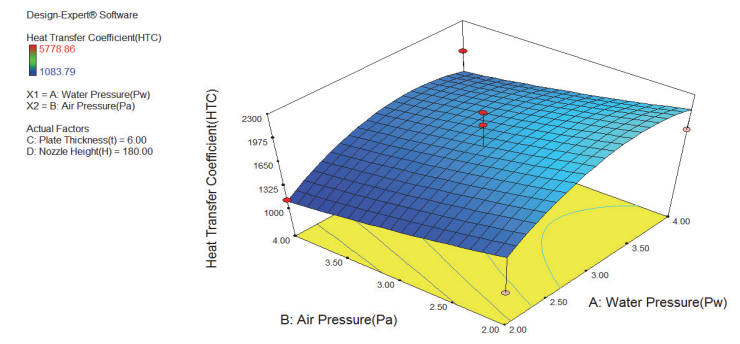

Fig. 2. Variation of HTC with respect to water pressure and air pressure

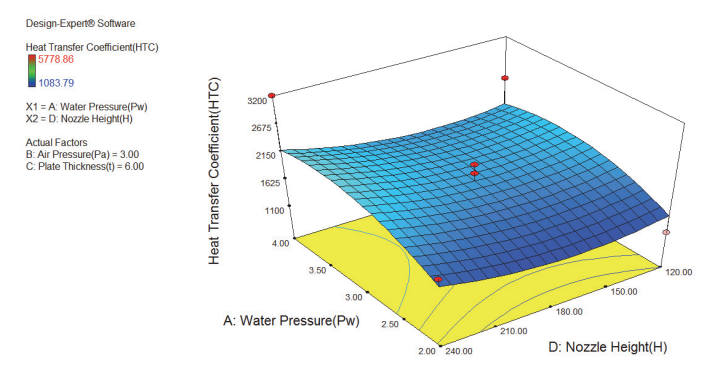

Fig. 4. Variation of HTC with respect to water pressure and nozzle height
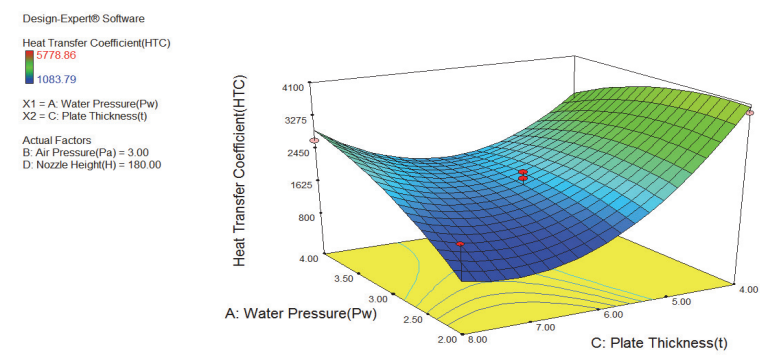

Fig. 3. Variation of HTC with respect to water pressure and plate thickness
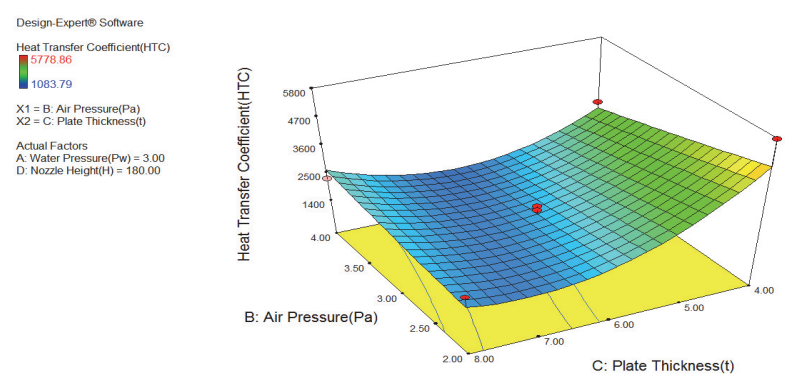

Fig. 5. Variation of HTC with respect to air pressure and plate thickness

Fig. 5 shows the variation of HTC with respect to air pressure and plate thickness. It is evident that the variation of HTC with variation of air pressure is less significant than plate thickness. It is found that with change in plate thickness the value of HTC increases and vice-versa. The maximum value of HTC is achieved at low level of plate thickness and high level of air pressure. Fig. 6 shows the variation of 
HTC with respect to nozzle height and air pressure. It is evident that the variation of HTC with variation of air pressure is less significant than nozzle height. The maximum HTC value is obtained at low level of air pressure and high level of nozzle height. Fig. 7 shows the variation of HTC with respect to nozzle height and plate thickness. It is evident that the variation of HTC with variation of nozzle height is less significant than plate thickness. It is found that with change in plate thickness the value of HTC increases and vice-versa. The maximum HTC value is obtained at high level of nozzle height and low level of plate thickness.

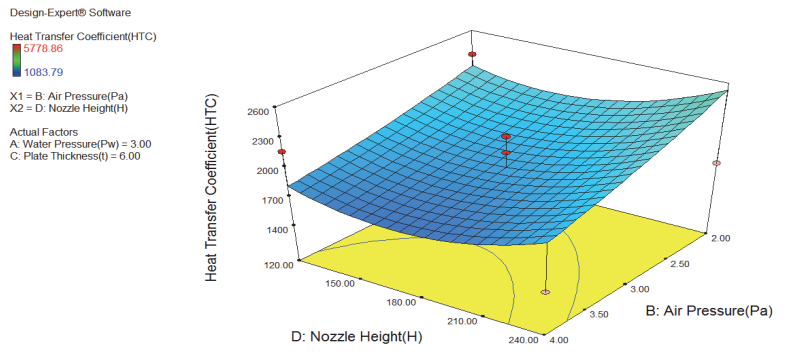

Fig. 6. Variation of HTC with respect to nozzle height and air pressure
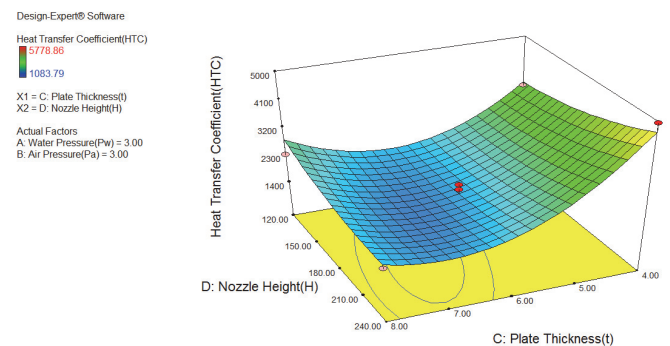

Fig. 7. Variation of HTC with respect to nozzle height and plate thickness

\subsection{Adequacy test of the Model}

The Model F-value of 2.97 implies the model is significant. There is only a $3.32 \%$ chance that a "Model F-Value" this large could occur due to noise. Values of "Probability $>$ F" less than 0.0500 indicate model terms are significant. In this case $\mathrm{C}, \mathrm{C}^{2}$ are significant model terms. The adequacy test data are presented in Table 4.

Table 4

Adequacy test of the model

\begin{tabular}{|c|c|c|c|c|c|c|}
\hline Source & $\begin{array}{l}\text { Sum of } \\
\text { Squares }\end{array}$ & DOF & $\begin{array}{c}\text { Mean } \\
\text { Square }\end{array}$ & $\begin{array}{c}\mathrm{F} \\
\text { Value }\end{array}$ & $\begin{array}{l}\mathrm{p} \text {-value } \\
\text { Prob }>\text { F }\end{array}$ & \\
\hline Model & 24662524.17 & 14 & 1761608.87 & 2.967716 & 0.0332 & Significant \\
\hline A-Water Pressure $(\mathrm{Pw})$ & 789986.3766 & 1 & 789986.3766 & 1.3308602 & 0.2711 & \\
\hline B-Air Pressure $(\mathrm{Pa})$ & 723460.879 & 1 & 723460.879 & 1.2187872 & 0.2912 & \\
\hline C-Plate Thickness(t) & 7904474.804 & 1 & 7904474.804 & 13.31637 & 0.0033 & \\
\hline D-Nozzle Height(H) & 150009.1106 & 1 & 150009.1106 & 0.2527147 & 0.6243 & \\
\hline $\mathrm{AB}$ & 74.9104203 & 1 & 74.9104203 & 0.0001262 & 0.9912 & \\
\hline $\mathrm{AC}$ & 2032905.705 & 1 & 2032905.705 & 3.4247595 & 0.0890 & \\
\hline $\mathrm{AD}$ & 5908.820329 & 1 & 5908.820329 & 0.0099544 & 0.9222 & \\
\hline $\mathrm{BC}$ & 1496343.969 & 1 & 1496343.969 & 2.5208342 & 0.1383 & \\
\hline $\mathrm{BD}$ & 4533.812772 & 1 & 4533.812772 & 0.0076379 & 0.9318 & \\
\hline $\mathrm{CD}$ & 870099.8422 & 1 & 870099.8422 & 1.4658244 & 0.2493 & \\
\hline $\mathrm{A}^{\wedge} 2$ & 476447.6432 & 1 & 476447.6432 & 0.8026534 & 0.3879 & \\
\hline $\mathrm{B}^{\wedge} 2$ & 5730.031295 & 1 & 5730.031295 & 0.0096532 & 0.9234 & \\
\hline $\mathrm{C}^{\wedge} 2$ & 7542213.309 & 1 & 7542213.309 & 12.706082 & 0.0039 & \\
\hline $\mathrm{D}^{\wedge} 2$ & 272554.7972 & 1 & 272554.7972 & 0.4591628 & 0.5109 & \\
\hline Residual & 7123089.505 & 12 & 593590.7921 & & & \\
\hline Lack of Fit & 6795023.555 & 10 & 679502.3555 & 4.1424741 & 0.2100 & Not Significant \\
\hline Pure Error & 328065.9499 & 2 & 164032.975 & R-Squared & 0.9579 & \\
\hline Cor Total & 31785613.68 & 26 & & Adj R-Squared & 0.7759 & \\
\hline
\end{tabular}

Values greater than 0.1000 indicate the model terms are not significant. If there are many insignificant model terms (not counting those required to support hierarchy), model reduction may improve your model. The "Lack of Fit F-value" of 4.14 implies the Lack of Fit is not significant relative to the pure error. There is a $21.00 \%$ chance that a "Lack of Fit F-value" this large could occur due to noise. Nonsignificant lack of fit is good -- we want the model to fit. The P value is less than 0.05 that signifies 
that the model in the $95 \%$ confidence level. It can also be seen that the normal plot of residuals lie well near probable values those are predicted. The normal plot of residual is depicted in Fig. 8.
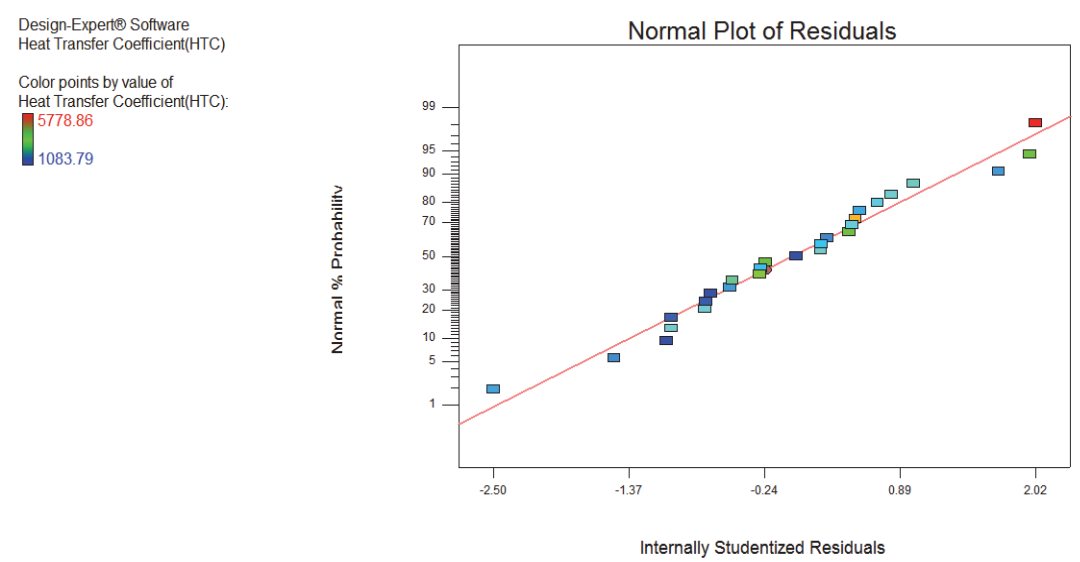

Fig. 8. Normal plot of the residual

\subsection{Desirability Function Analysis (DFA)}

Desirability function, proposed by Derringer and Suich, which has been widely used since then in industry. Its aim is to find operating conditions that ensure compliance with the criteria of all the involved responses and, at the same time, to provide the best value of compromise in the desirable joint response. Derringer's desirability function allows the analyst to find the experimental conditions (factor levels) to reach, simultaneously, the optimal value for all evaluated variables, including the researcher's priority during the optimization procedure. The steps involved in formation of composite function are follows:

Step 1: The individual Desirability $\left(\mathrm{d}_{\mathrm{i}}\right)$ for HTC is calculated from the data obtained during experiment for maximization using the formula:

$\mathrm{d}_{\mathrm{i}}=\left[\begin{array}{c}0 \text { if } X_{i}<X_{\min } \\ \frac{X_{i}-X_{\min }}{X_{\max }-X_{\min }} \text { if } X_{\min } \leq X_{i} \leq X_{\max } \\ 1 \text { if } X_{i}>X_{\max }\end{array}\right]$

Where; $d_{i}=$ individual desirability for $i^{\text {th }}$ response, $X_{i}=$ response value at $i^{\text {th }}$ experiment, $X_{\max }=$ Maximum value of the response, $X_{\min }=$ Minimum value of the response.

$\mathrm{D}_{1}=\frac{\mathrm{HTC}-\mathrm{HTCmin}}{\text { HTCmax }-\mathrm{HTCmin}}$

The desirability index values are tabulated in the Table 5.

Step 2: The second step is to calculate the composite desirability based on the given formula.

$\mathrm{D}=\left(\mathrm{d}_{1}{ }^{\mathrm{w} 1} \mathrm{X} \mathrm{d}_{2}{ }^{\mathrm{w} 2} \mathrm{X} \mathrm{d}_{3}{ }^{\mathrm{w} 3} \mathrm{X} \ldots \ldots \ldots . . . \mathrm{X} \mathrm{d}_{\mathrm{n}}{ }^{\mathrm{wn}}\right)^{1 /} \sum_{j=1}^{1} w_{j}$. The composite desirability data is reported in Table 6 . 
Table 5

Evaluated results of desirability function

\begin{tabular}{|c|c|c|c|c|}
\hline S1.No & Normalized HTC & WDI HTC & Composite Desirability & Rank \\
\hline 1 & 0.170221608 & 0.028975396 & 0.000839574 & 18 \\
\hline 2 & 0.822321173 & 0.676212111 & 0.45726294 & 2 \\
\hline 3 & 0.450299891 & 0.202769992 & 0.041115682 & 6 \\
\hline 4 & 0.270642358 & 0.073247286 & 0.005365167 & 9 \\
\hline 5 & 0.266080619 & 0.070798896 & 0.005012485 & 10 \\
\hline 6 & 0 & 0 & 0 & 27 \\
\hline 7 & 0.266080619 & 0.070798896 & 0.005012485 & 10 \\
\hline 8 & 0.008123645 & $6.59936 \mathrm{E}-05$ & 4.35517E-09 & 26 \\
\hline 9 & 0.072300441 & 0.005227354 & $2.73252 \mathrm{E}-05$ & 24 \\
\hline 10 & 0.150162453 & 0.022548762 & 0.000508447 & 21 \\
\hline 11 & 0.081611388 & 0.006660419 & 4.43612E-05 & 23 \\
\hline 12 & 0.600029706 & 0.360035648 & 0.129625704 & 3 \\
\hline 13 & 0.230774008 & 0.053256643 & 0.002836271 & 14 \\
\hline 14 & 0.201278927 & 0.040513207 & 0.00164132 & 15 \\
\hline 15 & 1 & 1 & 1 & 1 \\
\hline 16 & 0.283327742 & 0.080274609 & 0.006444015 & 8 \\
\hline 17 & 0.145288266 & 0.02110868 & 0.000445577 & 22 \\
\hline 18 & 0.163535223 & 0.026743769 & 0.000715229 & 19 \\
\hline 19 & 0.236023132 & 0.055706919 & 0.003103262 & 13 \\
\hline 20 & 0.194509223 & 0.037833838 & 0.0014314 & 16 \\
\hline 21 & 0.496542178 & 0.246554135 & 0.060788959 & 4 \\
\hline 22 & 0.175345753 & 0.030746133 & 0.000945325 & 17 \\
\hline 23 & 0.469921618 & 0.220826327 & 0.048764281 & 5 \\
\hline 24 & 0.339235083 & 0.115080442 & 0.013243512 & 7 \\
\hline 25 & 0.011060655 & 0.000122338 & $1.49666 \mathrm{E}-08$ & 25 \\
\hline 26 & 0.25708212 & 0.066091216 & 0.00436805 & 12 \\
\hline 27 & 0.161681365 & 0.026140864 & 0.000683345 & 20 \\
\hline
\end{tabular}

Table 6

Response table for composite desirability

\begin{tabular}{|c|c|c|c|c|c|}
\hline \multirow{2}{*}{ Process parameter } & \multicolumn{3}{|c|}{ Average composite desirability } & \multirow[b]{2}{*}{$\max -\min$} & \multirow[b]{2}{*}{ rank } \\
\hline & level 1 & level 2 & level 3 & & \\
\hline Water Pressure & 0.1307546 & 1.596167 & 0.063303 & 1.532863 & 2 \\
\hline Air Pressure & 1.0116013 & 0.721665 & 0.056958 & 0.954643 & 4 \\
\hline Plate Thickness & 1.6972815 & 0.063875 & 0.029068 & 1.668214 & 1 \\
\hline \multirow[t]{3}{*}{ Nozzle Height } & 0.0804469 & 1.208969 & 0.500808 & 1.128523 & 3 \\
\hline & Total Cumulative Desirability & 1.790225 & & & \\
\hline & Average cumulative desirability & 0.066304 & & & \\
\hline
\end{tabular}

Step 3: The third step is to determine the optimal condition based on highest composite desirability index. Since we have only a single response is calculated it by squaring the WDI i.e. w1 is taken as 2 . The obtained optimal conditions are provided in Table 7.

Table 7

Predicted Optimal Conditions

\begin{tabular}{cccc}
\hline \multicolumn{4}{c}{ Process Parameters } \\
\hline Water Pressure $(\mathrm{Pw})$ & Air pressure $(\mathrm{Pa})$ & Plate Thickness $(\mathrm{t})$ & Nozzle Height $(\mathrm{H})$ \\
\hline bar & bar & mm & mm \\
\hline 3 & 2 & 4 & 180 \\
\hline
\end{tabular}

Step 4: The last step is to calculate the value from experimental validation for confirming the optimality.

\subsection{Experimental validation}

Test was carried out at the predicted optimal parametric conditions, i.e. for $\mathrm{Pw}=3 \mathrm{bar}, \mathrm{Pa}=2 \mathrm{bar}$, plate thickness $=4 \mathrm{~mm}$ and nozzle height $=180 \mathrm{~mm}$. The procedure to compute the surface heat transfer coefficient (HTC) was followed. In the repeat experiment at the optimal conditions, the HTC was found 
to be $5778.93 \mathrm{~W} / \mathrm{m}^{2}{ }^{0} \mathrm{C}$. Comparing this data of HTC with the primary data given in Table 3 , test number 15 , cofirmed the experimental validatity with a small deviation of $0.07 \mathrm{~W} / \mathrm{m}^{2}{ }^{0} \mathrm{C}$. This deviation might be due to experimental error.

\section{Conclusion}

In the current research, optimization of the heat transfer coefficient of a heated steel plate by air water spray impingement cooling has been investigated with the predicted optimal conditions. Each of the process parameter has significant amount of influence upon the HTC. From the surface contur, it was very clear that HTC can be enhanced by maximizing the water pressure and minimizing the air pressure and plate thickness. The optimized value of the heat transfer coefficient under predicted optimal conditions found to be $5778.86 \mathrm{~W} / \mathrm{m}^{2}{ }^{0} \mathrm{C}$. This data had good experimental validation.

\section{References}

Aamir, M., Qiang, L., Xun, Z., Hong, W., \& Zubair, M. (2014). Ultra-Fast Spray Cooling and Critical Droplet Daimeter Estimation from Cooling Rate. Journal of Power and Energy Engineering, 2(04), 259.

Abbasi, B., \& Kim, J. (2011). Prediction of PF-5060 spray cooling heat transfer and critical heat flux. Journal of Heat Transfer, 133(10), 101504.

Díaz, A. J., \& Ortega, A. (2013). Investigation of a gas-propelled liquid droplet impinging onto a heated surface. International Journal of Heat and Mass Transfer, 67, 1181-1190.

Ebadian, M. A., \& Lin, C. X. (2011). A review of high-heat-flux heat removal technologies. Journal of Heat Transfer, 133(11), 110801.

Estes, K. A. (1996). Optimizing and predicting CHF in spray cooling of a square surface. Journal of Heat Transfer, 118, 672-679.

Fabbri, M., \& Dhir, V. K. (2005). Optimized heat transfer for high power electronic cooling using arrays of microjets. Journal of Heat Transfer, 127(7), 760-769.

Hou, Y., Liu, X., Liu, J., Li, M., \& Pu, L. (2013). Experimental study on phase change spray cooling. Experimental Thermal and Fluid Science, 46, 84-88.

Hou, L., Cheng, H., Li, J., Li, Z., Shao, B., \& Hou, J. (2012). Study on the cooling capacity of different quenchant. Procedia Engineering, 31, 515-519.

Martínez-Galván, E., Antón, R., Ramos, J. C., \& Khodabandeh, R. (2013). Effect of the spray cone angle in the spray cooling with R134a. Experimental Thermal and Fluid Science, 50, 127-138.

Naz, M. Y., Sulaiman, S. A., Ariwahjoedi, B., \& Ku Shaari, K. Z. (2013). Investigation of vortex clouds and droplet sizes in heated water spray patterns generated by axisymmetric full cone nozzles. The Scientific World Journal, 2013.

Pautsch, A. G., \& Shedd, T. A. (2005). Spray impingement cooling with single-and multiple-nozzle arrays. Part I: Heat transfer data using FC-72. International Journal of Heat and Mass Transfer, 48(15), 3167-3175.

Ravikumar, S. V., Jha, J. M., Sarkar, I., Mohapatra, S. S., Pal, S. K., \& Chakraborty, S. (2013). Achievement of ultrafast cooling rate in a hot steel plate by air-atomized spray with different surfactant additives. Experimental Thermal and Fluid Science, 50, 79-89.

Ravikumar, S. V., Jha, J. M., Tiara, A. M., Pal, S. K., \& Chakraborty, S. (2014). Experimental investigation of air-atomized spray with aqueous polymer additive for high heat flux applications. International Journal of Heat and Mass Transfer, 72, 362-377.

Seraj, M. M., \& Gadala, M. S. (2013, January). Wetting Front Propagation during Quenching of Aluminum Plate by Water Spray. In Proceedings of World Academy of Science, Engineering and Technology (No. 78, p. 858). World Academy of Science, Engineering and Technology (WASET).

Wendelstorf, J., Spitzer, K. H., \& Wendelstorf, R. (2008). Spray water cooling heat transfer at high temperatures and liquid mass fluxes. International Journal of Heat and Mass Transfer, 51(19), 4902-4910.

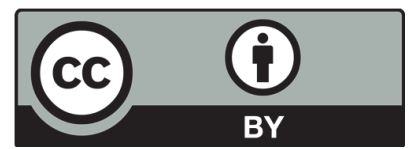

(C) 2016 by the authors; licensee Growing Science, Canada. This article is an open access article distributed under the terms and conditions of the Creative Commons Attribution (CC-BY) license (http://creativecommons.org/licenses/by/4.0/). 